\title{
Educators' Experiences of Establishing Social and Emotional Learning Pedagogies in an Elementary School With At-Risk Students
}

\author{
Ben Dyson ${ }^{a}$, Donal Howley ${ }^{*}$, , Yanhua Shen ${ }^{c}$, Seunghyun Baek ${ }^{d}$
}

Received
Revised
Accepted
DOl

24 February 2021

22 May 2021

15 June 2021

10.26822/iejee.2021.217

aBen Dyson, University of North Carolina at Greensboro, USA.

E-mail: bpdyson@uncg.edu

ORCID: https://orcid.org/0000-0001-5460-4836

Corresponding Author: Donal Howley, University of North Carolina at Greensboro, USA

E-mail: dfhowley@uncg.edu

ORCID: https://orcid.org/0000-0003-3534-6768

\section{Yanhua Shen, University of North Carolina at} Greensboro, USA

E-mail:y shen2@uncg.edu

ORCID: https://orcid.org/0000-0001-9827-4330

'Seunghyun Baek, University of North Carolina at

Greensboro, USA.

ORCID: https://orcid.org/0000-0002-3621-3011

E-mail: s_baek@uncg.edu

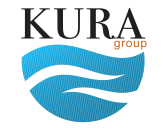

Copyright (c)

www.iejee.com

ISSN: 1307-9298

(C) 2021 Published by KURA Education \& Publishing. This is an open access article under the CC BYNC- ND license. (https://creativecommons.org/ licenses/by/4.0/)

\begin{abstract}
There exists a need to explore educators' initial experiences of working to establish Social and Emotional (SEL) pedagogies like Restorative Practices (RP) at elementary school level to help avoid slippage in implementation and inform and sustain long term positive change within school communities. Adopting a social ecological perspective, the purpose of this qualitative study was to explore educators' experiences of establishing SEL pedagogies in an elementary school with at-risk students. Utilizing interviews, focus group, and researcher field notes, 14 educators were asked to reflect on their understandings and ongoing experiences of SEL continued professional development and implementation of restorative practices. Applying inductive and deductive analysis, three themes emerged: Establishing the Significance of SEL through CPD; Putting SEL into Practice; and Realities of Establishing SEL. The insights of educators highlight where gaps existed and further support was required in order to incorporate the wider community and the fundamental role and influence of family in development of their students. Compared with the quantitative methodologies that have dominated SEL literature, qualitative methods help elicit the nuanced contextual opportunities and challenges educators experience when it comes to understanding and practically implementing SEL pedagogies holistically.
\end{abstract}

\section{Keywords: \\ Social and Emotional Learning, Continued Professional Development, Pedagogy, Restorative Practices, High-Needs Students.}

\section{Introduction}

esearch and practice involving the successful integration Rof Social and Emotional Learning (SEL) continues to be in sharp focus with educational researchers, policymakers, and practitioners (Garcia \& Weiss 2016; Jones et al., 2019b; Oberle et al., 2016). SEL can be defined as "the process through which individuals learn and apply a set of social, emotional, behavioral, and character skills required to 
succeed in schooling, the workplace, relationships, and citizenship" (Jones et al., 2019a p. 19). Within schooling, this process involves, but is not limited to, teachers implementing pedagogies which develop students' cognitive regulation, emotional processes, social/interpersonal skills, character, and mindset (Jones et al., 2017). Instead of implementing isolated SEL programs in schools, there have been calls to infuse SEL pedagogies into existing curricula "to enhance its sustainability and break the perceived barrier that there is a lack of time for SEL due to the pressures of the regular classroom curriculum" (Oberle \& Schonert-Reichl, 2017, p. 183). Establishing such pedagogies in schools to promote SEL requires a longitudinal approach to bring about cultural change (Morrison, Blood \& Thorsborne, 2005). However, such important work by teachers is all too often impeded by a lack of time, cultural and contextual sensitivity, ineffective design and implementation of pedagogies, limited training, struggles with conflict management, and a lack of support for teachers' wellbeing (Blyth et al., 2019; Kaynak Elcan, 2020). Literature has consistently highlighted failings in helping teachers experience effective SEL continued professional development (CPD) (Durlak, 2016), with schools lacking in-house experts and resources to facilitate teachers in "cohort-based, ongoing professional development experiences that provide continuous support" (Elias, 2019, p. 243). Such support is especially required for elementary schools with atrisk students, with challenging classroom, emotional climates, and limited mental health supports available for both teachers and students to enhance their SEL and broader learning (Brackett et al., 2011; Capella et al., 2008; Jacobson, 2019; Hoglund et al., 2015). The USA Department of Education (2021) defines this population as:

Students at risk of educational failure or otherwise in need of special assistance and support, such as students who are living in poverty, who attend highminority schools, who are far below grade level, who have left school before receiving a regular high school diploma, who are at risk of not graduating with a diploma on time, who are homeless, who are in foster care, who have been incarcerated, who have disabilities, or who are English learners.

Restorative Practices (RP) are peaceful, humanistic, non-punitive pedagogies for addressing harm, responding to violations of legal and human rights, and problem solving in cases of school indiscipline (Fronius et al., 2016; Ottmar et al., 2015; Wachtel, 2012; 2013), encompassing a multitude of "positive behavioral support approaches in a school that fosters communication, mutual respect, and understanding between all people" (Mansfield, Fowler, \& Rainbolt, 2018, p. 306). It has been shown to build affective skills by focusing on relational practices that empower students as well as offering a range of relevant learning opportunities (Dyson, Howley, \& Shen, 2019; Macready, 2009; Morrison et al., 2005). At the same time, research on school-based RP "is still at the infancy stage" (Fronius et al., 2016, p. 2). Within SEL research, there is a general lack of qualitative research and a predominance of quantitative research designs foregrounded in literature (Corcoran et al., 2018; Fraser et al., 2014; Hamre et al., 2013). There exists a need to explore educators' initial experiences of working to establish SEL pedagogies like RP at elementary school level to help avoid slippage in implementation and inform and sustain long term positive change within school communities. Compared with the predominantly quantitative methodologies found in meta-analyses and large-scale studies, a qualitative approach can help better identify and understand the nuanced opportunities and constraints educators experience when contextually implementing SEL pedagogies such as RP for the first time (Dyson et al., 2019; 2020). With this in mind, the purpose of this qualitative study was to investigate educators' experiences of establishing social and emotional learning pedagogies in an elementary school with at-risk students.

\section{Theoretical Perspective}

Social ecological theory (Bronfenbrenner, 1979, 1992) proposes that individuals develop within a multi-level system of environmental and social organizations, ranging from more proximal micro-level systems to more distal macro-level systems. School-based RP are conducted between students, teachers, administration, and the community (Karp \& Breslin, 2001; Mullet, 2014), with the goal of establishing "environments where members of the community take responsibility to repair harm when it occurs, hold each other accountable, and build skills in collective problem-solving" (Gonzalez, 2012, pp. 300-301). Considering this, the teaching and learning of SEL pedagogies like RP requires recognition of the range and influence of the active ecosystems within which children belong, learn, and live in, such as family, school, and communities (Crosby, 2015; Dusenbury et al., 2019; Papadopoulos, 2020). Teachers must learn to understand and work within these systems along with students, their families, and others and vice versa. Framing social and emotional development in schools through a social ecological perspective makes explicit links between and among different levels and considers transactions among people within their social and physical settings, over time and across personal, cultural, and institutional levels (Bronfenbrenner, 1979; Panter-Brick et al., 2006; Stokols, 1992). Thus, the development of students' SEL competencies can be influenced by teacher-student and peer relationships in the classroom (micro-level system), school climate 
and school administration (meso-level system), and outside of school in students' homes and communities (macro-level system) (Bornstein \& Lamb, 2015).

This study is guided by the SEL framework proposed by Jones and Bouffard (2012) grounded in the social ecological theory (Figure 1). Consisting of three domains (cognitive regulation, emotional processes, social and interpersonal skills), it presents the constructs of SEL from a broad educational and ecological perspective. In this way, the teaching of SEL is recognized as being influenced by multi-level environmental systems and factors, including culture and climate within and beyond schools (Jones \& Doolittle, 2017). The teacher's pedagogical skills help guide the child-level outcomes, leading to potentially improved child-level impacts. The social-cultural model extends out from the classroom and school to the wider community context. Understanding how these systems and factors intersect and impact the local environment can explain how SEL is successfully implemented or impeded by these factors (Jones et al., 2019b).

\section{Figure 1}

A framework for SEL (Jones and Bouffard, 2012)

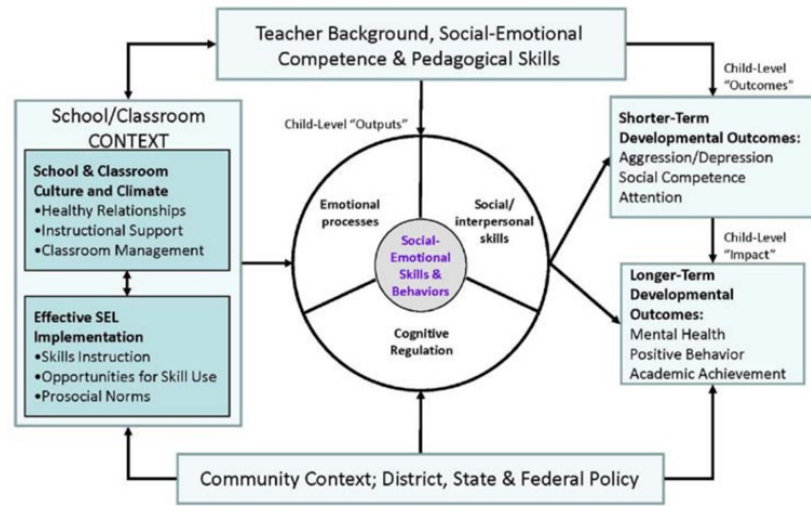

Supplementing this, our work is grounded in social constructivist learning theory as a research-informed and practical guide to school-based research in an effort to position and understand the establishment of SEL pedagogies with schooling and classrooms (Vygotsky, 1978). SEL pedagogies like RP requires teachers to facilitate social processes which help students to learn through their relationships and interactions with others within and beyond the school context with a view to transfer across multiple contexts (Lipponen, Rajala, \& Hilppö, 2018; Oberle \& Schonert-Reichl, 2017). Such processes allow teachers and students to recognize and challenge behavioral, individualistic, and fragmented approaches to SEL by offering a unified and profoundly social conceptualization of learning (Vadeboncoeur \& Collie 2013). In utilizing these conceptual frameworks to guide us, our intention is to build on existing knowledge through investigating the contextual establishment of SEL student pedagogies to improve learner outcomes.

\section{Methodology}

\section{Context}

The school and participants have all been given pseudonyms. This research used a case study design (Stake, 2006) to explore the establishment of SEL pedagogy in a K-5 Partnership School in North Carolina operated in collaboration with the school district and a local university. The North Carolina legislature established laboratory schools in 2016 to address the needs of low-performing students and schools and to prepare pre-service and in-service teachers to work more effectively in schools with at-risk students. Clonkeen served approximately 375 K-5 students (59\% African American; 20\% Caucasian; 11\% Hispanic; $10 \%$ Multi-Racial), $98 \%$ of whom come from lowincome families. In Clonkeen, students experienced regular conflict and disciplinary action. Teachers needed training in deescalating and working with students in proactive ways that focus on restorative tasks (Ex. class circle discussions) to work on positive conflict resolution. Using convenience sampling (Cooksey \& McDonald, 2019), 14 educators, including the school director, curriculum director, principal, assistant principal, social worker, physical education, special education, and generalist teachers agreed to participate. Participant information is provided in Table 1.

Teachers had varying degrees of training in SEL. Thomas was a trained counsellor and a grade 4 teacher. Jackie and Thomas attended multiple RP workshops to receive a certificate in order to be the lead trainers in RP for the teachers. The seven teachers in the SELT committee all had attended an extra full-day training in RP before the research project began. The remaining teachers had not previously participated in workshops on RP. Led by the Clonkeen curriculum leader, a Committee named the Social and Emotional Learning Team (SELT) was set up and met monthly to discuss and create action plans for the development of SEL at Clonkeen. The committee was made up of seven lead teachers, the Social Worker, curriculum leader, the school director, and two researchers from the university. One of the main initiatives was the whole school adoption of RP. During this study every teacher, the school leaders, and two researchers were actively involved in a two-day workshop on RP. To make this training contextually relevant to the teachers and sensitive to their needs, the school Social Worker and a grade 4 teacher participated in extensive instructor training on RP. After their training the Social Worker and teacher developed and facilitated this CPD for the teachers and leaders at Clonkeen. Then lead 
Table 1

Participant Information

\begin{tabular}{|c|c|c|c|}
\hline Name & Position & Race/Ethnicity & Years of Experience \\
\hline Teresa & Principal & African American & $\overline{23}$ \\
\hline Chris & School Director & Caucasian & 51 \\
\hline Auria & Associate Director for Curriculum & Caucasian & 32 \\
\hline Mary & Teacher Inquiry Director & Caucasian & 6 \\
\hline Matt & Assistant Principal & African American & 10 \\
\hline Jackie & Social Worker & African American & 10 \\
\hline James & K-5 PE Teacher & Caucasian & 6 \\
\hline Jess & Grade 5 Teacher & Caucasian & 24 \\
\hline Sarah & Grade 5 Teacher & Caucasian & 19 \\
\hline Anne & Grade 5 Special Education Teacher & Caucasian & 17 \\
\hline Kerry & Grade 4 Teacher & Caucasian & 17 \\
\hline Thomas & Grade 4 Teacher & Hispanic & 3 \\
\hline Brooke & Grade 2 Teacher & African American & 9 \\
\hline Hannah & Grade 2 Special Education Teacher & Caucasian & 3 \\
\hline
\end{tabular}

teachers were tasked to go back to Clonkeen and provide examples of how teachers could implement $\mathrm{RP}$ in their classrooms. In the CPD, the teachers were given a unifying message and they were trying to integrate RP into their teaching. To facilitate the CPD for teachers during the SELT committee meetings, teachers presented examples of their positive and negative experiences of implementing RP in their classrooms.

The principal investigator and three researchers were assigned to the school as 'critical friends' to teachers. The 'critical friends were the principal investigator/ researcher and three Ph.D. students. The principal investigator had 30 years' experience teaching, researching, and working in schools. The graduate students were all trained teachers and had taken qualitative and quantitative research methods classes. The teachers positively viewed the critical friends who visited the school on regular schedule. For example, the principal investigator visited the school 19 times during the study from between two and five hours.

Therefore, there were frequent interactions, informal interviews, and emails with teachers over eight months of one school semester outside of data collection procedures (July-February). In addition, the principal investigator attended and contributed to all school SELT meetings, attending eight meetings. We intended to focus on their conversations and interviews to understand how SEL CPD and the use of SEL pedagogies were represented in their comments. Before this research was initiated, an IRB was approved by a state university.

\section{Data Sources}

Sources used for data collection included interviews (12), a focus group (1), and researcher field notes (12) (Miles et al., 2014). There were 12 sets of field notes from 12 different days of visits, in 12 different classrooms. Interviews and focus groups were approximately 4560 mins in length and conducted before, during, and after classes, meetings, and the school day itself led by at least one member of the research team during organized visits to the school. These took place over the course of eight months (July-February). Educators were asked to reflect on their understandings and ongoing experiences of establishing SEL pedagogies in Clonkeen. This included questions on their understandings of SEL, previous and ongoing experiences of SEL CPD, examples of SEL pedagogies they implemented in class, and the challenges and opportunities that arose when implementing SEL pedagogies. Field notes, which included classroom observations, were also taken during these school visits.

\section{Data Analysis}

Qualitative procedures of inductive analysis and deductive analysis were used for data analysis (Miles et al., 2014). The process started by transcribing interviews, followed by importing all the data into NVivo 12 plus. This was followed by pattern coding, and then followed by axial coding, which aimed to identify conceptual links, discover relationships among categories, and generate themes by constant comparison and triangulation (Miles et al., 2014). Credibility was achieved by spending extended periods of time at Clonkeen with the teachers so 
that the continual presence would reduce possible distortions in data credibility. Member checks with participants were conducted. Importantly, throughout the process, peer debriefing with research colleagues and teachers was an iterative process of the data analysis. The dependability of the findings was addressed by laying out an audit trail for a colleague familiar with the research who collectively challenged the logic behind interpretations and the conclusions drawn, resulting in a much more reflective process and account. Confirmability was presented as a reflexive, self-critical account by triangulating our findings and interpretations supervised by a university professor with 20-years of schoolbased qualitative research experience with three research assistants. Trustworthiness was confirmed by continually challenging the interpretations of the findings, identifying conceptual links, and uncovering key themes and sub-themes through frequent peer debriefing with the researchers and the educators at Clonkeen (Lincoln \& Guba, 1985). The thematic findings which emerged from this process are presented in the next section.

\section{Findings}

This study analyzed the experiences of educators in establishing SEL pedagogies in an elementary school with at-risk students. From interviews, focus groups, and field notes, we elicited their voices and generated three main themes from a thorough data analysis process: Establishing the Significance of SEL through CPD; Putting SEL into Practice; and Realities of Establishing SEL.

\section{Establishing the Significance of SEL through CPD}

To assist in teaching SEL, all of the educators experienced varying forms of SEL CPD, which primarily focused on the implementation of RP within their classrooms and across the school's microsystem and mesosystem. This occurred through designated staff completing out of school workshops, followed by in-school training, monthly meetings, and informal interactions and follow-ups. All members of the SELT participated in out of school workshops. Following these, they then returned to Clonkeen and facilitated the rest of the staff in professional development focusing on the use of RP: "I was sent to a training for trainers. So now I can train people in RP specifically" (Thomas, Grade 4 Teacher); "I was trained as a trainer to be able to facilitate RP and professional development" (Jackie, Social Worker); "We received a lot of training upfront before the kids came...I felt like that was helpful" (Jess, Grade 5 Teacher). Following the in-school training prior to the beginning of the school year, the monthly staff meetings then helped the teachers discuss the ongoing establishment of SEL within their daily practices: "Every staff meeting we go over these things...It's giving awareness to all the staff about what we're doing and what we're trying to accomplish" (James, K-5 PE Teacher); "It has been very informative in helping us to think about how we respond to things" (Teresa, Principal). The value of discussing their experiences collectively and sharing ideas and resource was repeatedly alluded to: "The interactions that you have with your peers when you're going through it is so honest" (Sarah, Grade 5 Teacher); "We would share different ways we would use those discipline approaches and then talking about ones that didn't work and ones that did work" (Hannah, Grade 2 Special Ed Teacher). In addition to the monthly meetings, the teachers noted the ongoing informal guidance and support from the mesosystem level to implement SEL practices at a microsystem level in their classrooms. Teachers were also comfortable in seeking informal follow up support from the school social worker and administration who would regularly check in with and make themselves available to teachers outside of scheduled training and CPD when needed: "Our counselor is great... administration [and] is super helpful...we go to them if we ever need them" (Hannah).

Supplementing the emphasis placed on SEL practices within the ongoing experiences of $\mathrm{CPD}$, the educators interviewed recognized the significance of teaching SEL and prioritized it as a fundamental prerequisite for broader learning that extended beyond the school: "Our kids need to learn how to be productively interactive, in order then to gain the academic and social skills that they need to be not only good students, but good citizens" (Chris, School Director); "It's definitely important for our students to learn about kindness about compassion about treating, treating one another with respect" (Jackie). The use of RP was seen as significant in changing the school's approach to behavior: "It's not just trying to reinforce particular behaviors; it's trying to kind of change the thinking that's behind that" (Thomas). Emphasizing the significance of SEL meant educators recognized the need to providing a more holistic approach to schooling that went beyond core curriculum and content: "They can't learn academics if these base needs and comforts, safety and security aren't met first" (Sarah). We observed and wrote in our field notes that owing to their appreciation of the significance of SEL and ongoing CPD, teachers found themselves establishing SEL practices more frequently in their classrooms.

\section{Putting SEL into Practice}

Teachers identified a number of SEL practices they were implementing at the microsystem and mesosystem level which had derived from their experiences of CPD to assist in developing students' cognitive regulation, emotional processes, and social/interpersonal skills. 
RP, notably circle time and restorative conversations, and behavior modeling were seen as successful for teaching self-regulation and interpersonal skills. Circle time was seen as a successful practice for teaching SEL in groups. It allowed teachers to learn more about their students and improve teacher-student and peer relationships: "Too often students are spoken at, they're not spoken to...so we like to use the talking piece to hold them accountable for contributing to the conversation (Teresa); "For those teachers who are well schooled in doing a circle, they have been working well" (Chris); "My class they would circle all day long... it amazes me that they can open up like that...working on them being kind to each other". In smaller groups, restorative conversations were used in an effort to address and resolve conflict: "One person talks...then the other person gets to tell the other person what they did, what they don't like... then they just tell each other things that they like about each other to kind of restore that relationship" (Matt, Assistant Principal). In one-on-one situations, Jackie the Social Worker explained how she would get students to focus on "recognizing various different emotions...[and] discuss ways that they can deal with those emotions". Teachers also noted how modeling language and behaviors themselves to children as well as encouraging students to do so also was also a successful practice: "I should be able to control myself and that's what they need to see...the way that I try to keep my calm is very intentional and it's very difficult" (Sarah); "Having students be the models is so much more effective" (Hannah).

Through their experiences of establishing the significance of SEL, CPD, and subsequent implementation of practices, the educators observed development in students' SEL skills and behaviors. Teresa believed the establishment of SEL had led to better relationships and improved behavior across the school: "It's helped us develop a sense of community and it also has helped plant the seed of empathy within our students...definitely a decline in the number of days missed from school for discipline behavior". At the micro level, teachers noted that students were cooperating, communicating, and responding more constructively to them and their peers when learning in class: "They enjoy talking about themselves, they enjoy learning about their peers, they enjoy learning about their teachers, they enjoy knowing what happens if there's a conflict (Jackie); "They're learning how to work together a lot" (Kerry, Grade 4 Teacher); "I feel like students learn better and they're more open and receptive to ideas and with SEL" (Thomas).

\section{The Realities of Establishing SEL}

While teachers' experiences of putting their SEL CPD into practice with their students had led to improvements in practice and behavior, they were also faced with overcoming numerous hurdles that such work involves. These included differing understandings of SEL processes, embedding whole school buy-in, negotiating the sensitive school climate, facilitating time and care, and recognizing the role of family and community.

\section{Understanding of SEL Processes}

During the early stages of school wide SEL implementation, educators exhibited distinctive understandings of SEL processes, with no clear unified understanding of SEL or the processes involved to implement SEL appropriately. Instead, they interpreted and described SEL processes in different ways centered around supporting students' emotional wellbeing through deliberately developing social skills and behaviors, as well as addressing students' individual needs. This meant certain processes were identified and prioritized over others. At the mesosystem level, administrative educators broadly understood SEL as developing emotional well-being within the school community. Chris described SEL processes as "behaviors and skills and dispositions that people need to learn in order to interact with one another in productive ways," while Teresa identified them as "skill sets that allow you to be a part of a community." Jackie focused more on empathy, perspective-taking, and pro-social skills: "[Students] learn about kindness; about compassion; about treating one another with respect." Behaviors and skills were repeatedly identified and described in different ways. At the microsystem level, James described the main processes of SEL in terms of social and interpersonal skills: "working together collaboratively, feeling, problem-solving, thinking together." Thomas and Matt focused on self-awareness and self-management respectively: "understanding yourself and how you interact with other people in a positive way"; "build empathy and have students think about their behaviors and think about how their behaviors shape or affect others". Sarah was primarily concerned with students' emotional and behavioral regulation: "they can't learn academics if these base needs and comforts, safety, and security aren't met first." For Hannah, her understanding of SEL was contextual and centered on the "students' needs" rather than any particular set of processes: "I have had a few students that have the label of emotional disturbance and then also have students that have a disability...but need those needs met as well".

\section{Embedding Whole-School Buy-In}

The principal and assistant principal expressed uncertainty regarding the extent to which SEL practices were being embraced and implemented with fidelity across the mesosystem despite the CPD everyone had received and continued to participate 
in: "[Teachers] are struggling, and being very honest, possibly being defeated in their classrooms" (Teresa); "I see it done with fidelity in some classrooms, maybe not all" (Matt). Such uncertainty was also noted amongst teachers: "Having everybody on board and doing this as a school might be a struggle" (Thomas); "I don't know if other teachers in the school are at the point where they feel overwhelmed?" (Sarah). Despite the efforts to establish SEL pedagogy as common practice, there existed a need to develop CPD and further buy-in across the school: "Most teachers struggle to incorporate RP, even though all the teachers had attended a two-day training and ongoing guidance" (FN, FB, December, 2019); "If it's going to be implemented correctly it needs to be $100 \%$ buy-in, everybody in the building speaking the same language, doing the same structure, the circles, and the questionings" (James).

\section{Sensitive School Climate}

At the microsystem level, Classroom teachers openly struggled with the shift in practice, which required them to regularly handle emotionally charged and sensitive encounters: "Some days I don't want to talk about it. Some days I just want to, you know, go sit down and move on" (Brooke, Grade 2 Teacher). When it came to SEL, Hannah struggled to know where to place her focus: "To heavily target one behavior when there are so many needs...that's a huge challenge". Dealing with students' SEL needs individually while still maintaining classroom management and a safe environment was a constant challenge: "Inappropriate behaviors are taking away from class time. And that becomes very frustrating" (Teresa). Teachers reported dealing with frequently charged emotional incidents in their classrooms: "I just feel a lot of anger...maybe a little bit of resentment and resistance. I see a lot of kids who are just sad" (Mary, Teacher Inquiry Director); "You turn around and they can just hate each other. And violently act against each other after they were being supportive... you can't turn your back for a second" (Sarah). The classroom situations and contextual challenges teachers were faced with in their teaching practice highlighted the difficult process of transferring CPD theory and learning into practice in their classrooms.

\section{Time and Care}

Educators noted that teaching SEL required a considerable amount of time and care: "You can't just give them a list and say, here, go do this. They've got to feel it...time is a tremendous inhibitor." (Chris); "It's a slow process...I think because it's a gradual process. That's a challenge." (Teresa); "It takes a lot of, a lot of time, a lot of energy" (Brooke). This was also reflected in field notes: "These teachers seem to sincerely care about their students, but they know that it takes time for meaningful change" (FN, FB, February, 2020). Teachers' time and care was directed towards their immediate classrooms at the microsystem level rather than the school as a whole: "I've been so deep in my class of needs, it's all I can do to get through my days and keep my sanity and try to keep my calm" (Sarah). Teachers emphasized the need for additional time to provide and seek emotional support and positive mentoring amongst themselves and administration as part of their CPD.

\section{Reimagining the Role of Family and Community}

When it came to the macrosystem, teachers acknowledged that the role of students' families and the communities had a huge bearing on their SEL development in school. However, rather than viewing family and the community as a positive element that could facilitate SEL, educators regularly identified it as an inhibitor: "I feel like in a population like ours, it has to be taught more so than in other populations where it may be a natural experience at home" (Teresa). While educators had observed early success in their immediate classrooms and around the school, extending this work beyond the school gates was something that they had struggled to get to grips with. They regularly cited shortcomings in their knowledge about students' lives beyond the school. There was at times a sense of acceptance and despondency in the language used by teachers around macro issues such as poverty, crime, violence, and trauma in the community which impacted students' learning and school engagement: "There's so much all the time with so many of them. Like 'Oh, another stabbing, another shooting, another murder"' (Sarah). "A lot of our students go home to a very non-nurturing destructive area or household...when they come here to us, they still have their defense up. They're being taught to have this very tough skin" (James). The "home-school disconnect" observed by Taylor was a source of frustration for many teachers and made it difficult for them to reimagine the role of family and community in the process, instead drawing deficit conclusions/assumptions: "If they aren't emotionally prepared, they end up in jail, they commit petty crimes" (Kerry); "We want to use the same strategies at school, at home, but parents are so overwhelmed too that that's hard to keep consistent" (Hannah); "I think a lot of parents, if somebody has done something to their child, they want that person punished" (Thomas). The pedagogical practice of circle time repeatedly elicited the challenging home life students lived in which led teachers to feel uncomfortable: "I think that things that come out [in the circles] are very, very disturbing" (Jess); It's overwhelming, some of their revelations that come out in front of the whole group are just a lot to take in" (Anne, Grade 5 Special Education Teacher). 
As principal, Teresa recognized the need to bridge the disconnect between school and family: "I think [SEL] starts at home, but I think then it carries over, you know, into school". This was further echoed further by the assistant principal Matt: "Right now we don't have anything planned to talk to parents about their practices...that is another piece... giving them some tools that we use in school". While the early experiences of establishing SEL and CPD had brought about observed improvements at the microsystem and mesosystem levels in practice and behavior, educators in Clonkeen were acutely aware of the realties establishing a SEL pedagogy brought with it. Moreover, they had yet to fully reimagine and consider the need for such work to go beyond the school and into the community. In the next section, we discuss these contextually relevant findings in relation to the literature and look to inform future practice and CPD experiences for establishing SEL in an elementary school with at-risk students.

\section{Discussion}

Adopting a qualitative approach exploring educators' experiences of establishing SEL pedagogy in an elementary school with at-risk students helps demonstrate how the teaching and establishment of SEL is influenced by many multi-level environmental and political factors, including culture and climate (Dyson et al., 2011; Jones \& Doolittle 2017). Pedagogies that prioritize SEL like RP are increasingly seen as critical prerequisites for at-risk students and can contribute to higher academic achievement (Hamre et al., 2013; Oberle et al., 2016). However, the priority of many elementary schools at present is to educate students to master essential academic content areas with an emphasis placed on a common core of subjects, assessments, and standardization (Berry, 2011). Frydenberg and Muller (2017) believe initiatives "that are not embedded in school culture tend to have a [short] shelf life" (p. 386). Within Clonkeen Elementary, there was a conscious emphasis being placed on the significance of SEL and its establishment at the microsystem and mesosystem levels in classroom practice and school culture through provisions for CPD for longer term developmental impact. The teachers established their own SEL support group that met monthly to discuss issues and concerns surrounding SEL in their classes, sporting events, and gymnasium. Not only was the focus on developing students' SEL, in addition the educators recognized the need to develop their own SEL competency. In this way, the knowledge they were sharing and generating helped support and inform their use of SEL pedagogies and allowed them to align and adapt these widely accepted practices to extend beyond their respective classrooms and across the school community. There was an emphasis on the need for refinement and continuous improvement, which led to new understandings and consistent approaches amongst all educators in the school.

School connectedness has been identified as a significant mediator to school climate and conduct problems (Panayiotou et al., 2019). Considering the microsystem and mesosystem, when schools like Clonkeen explicitly cultivate a culture of care and emotional support, this can in turn change the behavior of everyone within it (Espelage at al., 2013). Literature on school discipline highlights a significant inverse relationship between suspensions and achievement, along with a significant positive relationship between suspensions and dropouts (Noltemeyer et al., 2015). Too often, researchers and practitioners are more concerned with teaching and idealizing good behaviors that they forget the need to acknowledge and teach students that, for example, conflict is a natural and normal part of social interaction. In line with best practice, these educators tried to implement RP to teach SEL, not in isolation, but instead deliberately and consistently within the generalized curriculum in an effort to "support children's use and internalization of skills to support a positive classroom environment" (Schonert Reichl, 2019, p. 226).

Providing staff with consistent CPD and opportunities to develop their SEL competence, pedagogical skills, and share and reflect their experiences led to further establishment of RP that attempted to promote "communication, mutual respect, and understanding between all people" (Mansfield et al., 2018, p. 306). As teachers worked together and learned through CPD how to put SEL into practice, they could see gradual improvements in their own practice at the microsystem level which in turn was leading to short term developmental outcomes (Jones \& Bouffard, 2012). In doing so, teachers were working with their students to create a healthier school climate by reinforcing SEL throughout the school day beyond singular classrooms (Smith \& Low, 2013). Gradually, educators in Clonkeen were developing and establishing these practices and were able to observe the beginning of a shift in student classroom behavior towards "an environment that consistently fosters awareness, empathy, and responsibility in a way that is likely to prove far more effective in achieving social discipline than our current reliance on punishment and sanctions" (Wachtel, 2012, p. 9). Key to this was a consistent modelling of behavior and language by teachers which embodied SEL, and which students could experience and demonstrate with staff, amongst themselves, and potentially take home with them. In this way, SEL pedagogies were becoming a regular part of day-to-day schooling alongside the accomplishment of broader learning objectives. The initial CPD initiatives were successful in transforming 
school culture and classroom environments, albeit in modest ways.

Yet, subjectively exploring the "black-box" of how all this was occurring and the extent to which the establishment of SEL pedagogies played out in practice demonstrates that such an approach was far from plain sailing. People influence their settings, and their settings exert influence over people's behaviors through cyclical processes (Estabrooks et al., 2008). The lived experiences of the educators in this study provide information that their ability to develop and implement SEL practices in the early days of the process varied and often lacked cohesion. In their classrooms, at the microsystem level, teachers had few opportunities to learn by collaborating with each other through forums facilitating voice, reflection, support, and improved practice (Darling-Hammond \& McLaughlin, 2011; Darling-Hammond et al., 2020). At the mesosystem level their combined experiences of CPD varied outside of their monthly meetings. Individual understandings of what exactly they were looking to accomplish and target collectively at times differed amongst teachers implementing SEL at the microsystem level in their own classrooms. This further compounded by constraints of a high standardized academic curriculum and challenging situations involving at-risk students. Inconsistent implementation remains a significant obstacle for the implementation of SEL in classrooms (Evans et al., 2015). Zhai et al. (2015) attribute this to variations in program definitions, designs, and fidelity of implementations. Alongside improvements, educators in Clonkeen openly observed and expressed difficulty in in cursory implementation, fidelity in use, whole-school buy-in, and appropriate adult modelling. Staff were unquestionably dedicated in their broad commitment to SEL at the mesosystem level in their school meetings. However, as such work extended out from the classrooms and into school and family life, significant slippage was occurring and the extent to which the skills learned in school were transferring into students' broader lives was still difficult to determine.

The reality of their contextual conditions and frequent adverse classroom incidences weighed heavily on teachers. Even experienced and capable teachers were challenged in implementing RP, and their underlying beliefs, perceptions, and attitudes about programming appeared to influence implementation (Humphrey et al., 2018). There existed a mixed understanding and focus among educators as to the SEL skills they were each targeting and prioritizing. Reflecting the many factors involved in the process from a social ecological perspective, teachers' own SEL competence and well-being before, during, and after their day's work also played a pivotal role in influencing the infusion of SEL (Kaynak Elcan, 2020;
Schonert- Reichl et al., 2015; Weissbourd et al., 2013). Implementing RP authentically was a daunting task for teachers as it led to managing moments of conflict and behavior, which may otherwise have gone unaddressed. A collaborative and holistic pedagogy such as RP asks teachers and students to embrace all the ranging facets of human emotion and behavior and is necessary in order to help teach SEL meaning fully (Darling-Hammond et al., 2020; Ginwright, 2016). This warts and all approach to SEL led to difficult moments on a day-to-day basis for students, and the educators themselves, who themselves admittedly often struggled to comprehend and manage.

Research into change in schools has usually been focused at either a macrosystem level or a microsystems level (Fullan, 1999, 2005). At the microsystem level there existed a clear need to further collectively uplift teachers as learners within their classrooms, providing them with more holistic and regular CPD to improve their understanding and establishment of SEL pedagogies, which then valued and reflected the whole school's culture at the mesosystem level to enhance broader learning (Elias \& Leverett, 2011). However, in a systematic fashion, we propose that at Clonkeen, the macrosystem impacts both the teacher and child through its indirect influence on the microsystem and mesosystem (Espelage et al., 2013). The qualitative insights of educators in Clonkeen helped highlight where gaps existed and further support was critically required in order to incorporate the wider community (macrosystem level) and the fundamental role and influence of family in development of their students, but of themselves also. This was especially the case when it came to establishing SEL beyond the school and in the wider community. The educators' capacities to reimagine and engage with the culture of the wider community to transcend SEL beyond the school, even at such an early stage, was made problematic by their preexisting perceptions of the community. Understanding how to better manage and bridge these ecological gaps is just as necessary for effective fostering of desired competencies in students (Ee \& Wong, 2014; Zinsser et al., 2014). This was something the educators needed to learn by their own admission. While much had been accomplished by educators at Clonkeen, further persistence and effort was needed to establish and develop SEL practices beyond the initial phase of implementation so as to contribute to long term outcomes and improved academic achievement.

\section{Conclusion}

Considering the establishment of SEL from a social ecological perspective within Clonkeen highlights the need to understand the dynamic relationships between people and their environments. Successful 


\section{iejee}

SEL approaches need to target multiple levels of the school social-ecological system. While meta-analyses support the general effectiveness of SEL programs, there is a lack of research focusing on differential effectiveness (i.e., what works, for whom it works, and under what conditions) (Jones et al., 2017). While RP are believed to have the potential to foster the type of reflection that enhances students' SEL development, further empirical evidence is still required in order to confirm this (Gregory \& Fergus, 2017; Sumner, Silverman, \& Frampton, 2010). This is especially the case when it comes to infusing SEL pedagogies such as RP within a generalized curriculum rather than in isolation. Unfortunately, the type of experiences and work observed in Clonkeen doesn't always result and manifest itself in instant transformation and improved academic test scores. Compared with the quantitative methodologies that have dominated SEL literature, this study shows us the nuanced contextual opportunities and challenges educators experience when it comes to initially understanding and practically establishing and implementing SEL pedagogies holistically. Just as recognizing what works in establishing and implementing SEL pedagogies in specific contexts, so too must such work be juxtaposed with an appreciation of what impedes it. Doing so openly and honestly under real-world conditions such as those the educators in Clonkeen faced every day can help better understand and enhance their translational value into and beyond the natural classroom setting (Carroll, Bower, Ashman, \& Lynn 2017; Merrell \& Gueldner, 2012).

Wigelsworth et al. (2016) who argue that rather than questioning "does SEL work?" we should instead question "how does SEL work (or, why does it fail?)?" (p. 368). While gradually developing SEL on the surface, a qualitative look shows the extent and intricacies of the realities educators faced in their commitment to such work and the slippage from theory to practice which was occurring. The ongoing CPD was beneficial, local knowledge and innovation can only be found through further working openly and honestly within the contexts of teachers' communities in order to theorize and construct their work (Cochran-Smith \& Lytle, 1999). In order to meet the cultural sensitivity of schools like Clonkeen, more formal and localized communities of practice are needed to help cultivate such a unified approach to establishing SEL (Darling-Hammond \& McLaughlin, 2011; Darling-Hammond et al., 2020). Using qualitative methods within a mixed-methods research design that gathers empirically based-evidence could provide a deeper understanding which can help us assess how CPD impacts educators' effectiveness in teaching SEL beyond just quantitative data. There is a lack of qualitative research and a predominance of quantitative research designs foregrounded in SEL literature (Dyson et al., 2019; 2020; Corcoran et al., 2018;
2020; Hamre et al., 2013) and in our research we seek a deeper understanding of the realities teachers' face every day doing the important work they do. In closing, we emphasize that on deeper qualitative inspection, initial student SEL learning outcomes that arose from educators' efforts in Clonkeen while continuing to be a work in progress, were certainly worthwhile - something which can often be overlooked using quantitative methods. Further appreciation and research as to how such well-intentioned work is made more successful or inhibited is necessary if teachers are to help students to perform effectively in schooling and improve academic achievement, while also supporting and preparing them to negotiate their lives beyond the classroom and into the future.

\section{References}

Berry, R. (2011). Assessment reforms around the world. In R. Berry\& B. Adamson (Eds.), Assessment reform in education: Policy and practice (pp. 89-102). London, UK: Springer

Blyth, D.A., Borowski, T., Farrington, C.A., Kyllonen, P., \& Weissberg, R.P. (2019). Ten criteria for describing and selecting SEL frameworks. Chicago, IL: Collaborative for Academic, Social, and Emotional Learning.

Bornstein, M. H., \& Lamb, M. E. (2015). Developmental Science: An Advanced Textbook (7th ed.). Mahwah, NJ: Erlbaum.

Brackett, M. A., Reyes, M. R., Rivers, S. E., Elbertson, N. A., \& Salovey, P. (2012). Assessing Teachers' Beliefs About Social and Emotional Learning. Journal of Psychoeducational Assessment, 30(3), 219236. https://doi.org/10.1177/0734282911424879

Bronfenbrenner, U. (1979). The Ecology of Human Development. Experiments by Nature and Design. Cambridge, MA: Harvard University Press.

Bronfenbrenner, U. (1992). Ecological systems theory. In R. Vasta (Ed.), Six theories of child development: Revised formulations and current issues (p. 187249). Jessica Kingsley Publishers.

Cappella, E., Frazier, S. L., Atkins, M. S., Schoenwald, S. K., \& Glisson, C. (2008). Enhancing schools' capacity to support children in poverty: An ecological model of school-based mental health services. Administration and Policy in Mental Health and Mental Health Services Research, 35(5), 395. 
Carroll, A, Bower,J.M., Ashman, A.F., \& and Lynn, S. (2017). Early Secondary High School-A Mindfield ${ }^{\oplus}$ for Social and Emotional Learning. In Frydenberg, E., Martin, A. J., \& Collie, R. J. (Eds) Social and Emotional Learning in Australia and the AsiaPacific (pp.335-352). Singapore: Springer

Cochran-Smith, M., \& Lytle, S. L. (1999). Relationships of knowledge and practice: Teacher learning in communities. Review of research in education, 24(1), 249-305.

Cooksey, R., \& McDonald, G. (2019). Surviving and Thriving in Postgraduate Research. Springer Singapore. https://doi.org/10.1007/978-981-137747-1

Corcoran, R. P., Cheung, A. C. K., Kim, E., \& Xie, C. (2018). Effective universal school-based social and emotional learning programs for improving academic achievement: A systematic review and meta-analysis of 50 years of research. Educational Research Review, 25, 56-72. https:// doi.org/10.1016/j.edurev.2017.12.001

Darling-Hammond, L., Flook, L., Cook-Harvey, C., Barron, B., \& Osher, D. (2020). Implications for educational practice of the science of learning and development. Applied Developmental Science, 24(2), 97-140. https://doi.org/10.1080/10 888691.2018 .1537791

Darling-Hammond, L., \& McLaughlin, M. W. (2011). Policies That Support Professional Development in an Era of Reform. Phi Delta Kappan, 92(6), 8192. https://doi.org/10.1177/003172171109200622

Durlak, J. A. (2016). Programme implementation in social and emotional learning: Basic issues and research findings. Cambridge Journal of Education, 46(3), 333-345.

Dyson, B., Howley, D., \& Shen, Y. (2019). Teachers' perspectives of social and emotional learning in Aotearoa New Zealand primary schools. Journal of Research in Innovative Teaching \& Learning, 12(1), 68-84. https://doi.org/10.1108/ JRIT-02-2019-0024

Dyson, B., Howley, D., \& Shen, Y. (2020). 'Being a team, working together, and being kind': Primary students' perspectives of cooperative learning's contribution to their social and emotional learning. Physical Education and Sport Pedagogy, 1-18. https://doi.org/10.1080/1740898 9.2020 .1779683
Dyson, B., Wright, P. M., Amis, J., Ferry, H., \& Vardaman, J. M. (2011). The Production, Communication, and Contestation of Physical Education Policy: The Cases of Mississippi and Tennessee. Policy Futures in Education, 9(3), 367-380. https://doi. org/10.2304/pfie.2011.9.3.367

Espelage, D. L., Rao, M. A., \& Rue, L. D. L. (2013). Current research on school-based bullying: A socialecological perspective. Journal of Social Distress and Homelessness, 22(1), 21-27. https:// doi.org/10.1179/1053078913Z.0000000002

Estabrooks, P. A., Fisher, E. B., \& Hayman, L. L. (2008). What is Needed to Reverse the Trends in Childhood Obesity? A Call to Action. Annals of Behavioral Medicine, 36(3), 209-216. https://doi. org/10.1007/s12160-008-9070-7

Ee, J., Zhou, M., \& Wong, I. (2014). Teachers' Infusion of Social Emotional Learning. Journal of Teaching and Teacher Education, 210(1183), 1-19. https:// doi.org/10.12816/0004407

Elias, M. J. (2019). What If the Doors of Every Schoolhouse Opened to Social-Emotional Learning Tomorrow: Reflections on How to Feasibly Scale Up High-Quality SEL. Educational Psychologist, 54(3), 233-245. https://doi.org/10.10 80/00461520.2019.1636655

Elias, M. J., \& Leverett, L. (2011). Consultation to Urban Schools for Improvements in Academics and Behavior: No Alibis. No Excuses. No Exceptions. Journal of Educational and Psychological Consultation, 21(1), 28-45. https://doi.org/10.1080 $/ 10474412.2010 .522877$

Evans R., Murphy S., \& Scourfield J. (2015). Implementation of a school-based social and emotional learning intervention: Understanding diffusion processes within complex systems. British Educational Research Journal, 16, 754764. doi: 10.1007/s11121-015-0552-0

Fraser, M. W., Thompson, A. M., Day, S. H., \& Macy, R. J. (2014). The Making Choices Program: Impact of Social-Emotional Skills Training on the Risk Status of Third Graders. The Elementary School Journal, 114(3), 354-379. https://doi.org/10.1086/674055

Fronius, T., Darling-Hammond, S., Persson, $H$., Guckenburg, S., Hurley, N., Petrosino, A. (2019). Restorative justice in U.S. schools: An updated research review. Woburn, MA: WestEd Justice and Prevention Research Center. 
Frydenberg, E. \& Muller, D. (2017) SEL Approaches that Have Worked: A Case Study of the Role of Formative Evaluation. In Frydenberg, E., Martin, A. J., \& Collie, R. J. (Eds) Social and Emotional Learning in Australia and the Asia-Pacific (pp.371-389). Singapore: Springer

Fullan, M. (1999) Change Forces: the sequel. London: Falmer Press.

Fullan, M. (2005) Leadership and Sustainability Systems: thinkers in action. Thousand Oaks, CA: Corwin Press.

García, E., \& Weiss, E. (2016). Making Whole-Child Education the Norm: How Research and Policy Initiatives Can Make Social and Emotional Skills a Focal Point of Children's Education. Economic Policy Institute. https://eric.ed.gov/?id=ED568889

Ginwright, S. (2016). Hope and healing in urban education: How urban activist and teachers are reclaiming matters of the heart. New York: Routledge.

Gregory, A., \& Fergus, E. (2017). Social and Emotional Learning and Equity in School Discipline. The Future of Children, 27(1), 117-136. JSTOR.

Gonzalez, T. (2012). Keeping kids in schools: Restorative justice, punitive discipline, and the school to prison pipeline. JL \& Educ., 41, 281.

Hamre, B. K., Pianta, R. C., Downer, J. T., DeCoster, J., Mashburn, A. J., Jones, S. M., ... Brackett, M. A. (2013). Teaching through interactions: Testing a developmental framework of teacher effectiveness in over 4,000 classrooms. The Elementary School Journal, 113(4), 461-487.

Hoglund, W. L. G., Klingle, K. E., \& Hosan, N. E. (2015). Classroom risks and resources: Teacher burnout, classroom quality and children's adjustment in high needs elementary schools. Journal of School Psychology, 53(5), 337-357. https://doi. org/10.1016/j.jsp.2015.06.002

Humphries, M. L., Williams, B. V., \& May, T. (2018). Early Childhood Teachers' Perspectives on SocialEmotional Competence and Learning in Urban Classrooms. Journal of Applied School Psychology, 34(2), 157-179. https://doi.org/10.1080 $/ 15377903.2018 .1425790$
Jacobson, S. (2019). Social Justice Leadership for Academic, Organisational and Community Sustainability in High-Needs Schools: Evidence from New Zealand, Belize and the USA. In P.S. Angelle \& D. Torrence (Eds.) Cultures of Social Justice Leadership (pp. 21-42). Cham, Switzerland: Palgrave Macmillan

Jones, S., Bailey, R., \& Kahn, J. (2019a). The Science and Practice of Social and Emotional Learning: Implications for State Policymaking. State Education Standard.

Jones, S. M., \& Bouffard, S. M. (2012). Social and Emotional Learning in Schools: From Programs to Strategies and commentaries. Social policy report, 26(4), 1-33.

Jones, S., Brush, K., Bailey, R., Brion-Meisels, G., Mclntyre, J., \& HKhan, J. (2017). Navigating SEL from the inside out. looking inside and across 25 leading SEL programs: a practical resource for schools and OST providers. Cambridge, MA: Harvard Graduate School of Education.

Jones, S. M., \& Doolittle, E. J. (2017). Social and Emotional Learning: Introducing the Issue. The Future of Children, 27(1), 3-11.

Jones, S. M., McGarrah, M. W., \& Kahn, J. (2019b). Social and Emotional Learning: A Principled Science of Human Development in Context. Educational Psychologist, 54(3), 129-143. https://doi.org/10.10 80/00461520.2019.1625776

Karp, D. R., \& Breslin, B. (2001). Restorative justice in school communities. Youth \& Society, 33(2), 249272 .

Kaynak Elcan, N. (2020). A close look at teachers' lives: Caring for the well-being of elementary teachers in the US. Journal of Emotional Education, 12(1), 19-34.

Lipponen, L., Rajala, A., \& Hilppö, J. (2018). "Compassion and Emotional Worlds in Early Childhood Education." In C.A. Pascal, T. Bertram, and M. Veisson (Eds) Early Childhood Education and Change in Diverse Cultural Contexts (pp. 162173). New York: Routledge.

Macready, T. (2009). Learning social responsibility in schools: A restorative practice. Educational Psychology in Practice, 25(3), 211-220. https:// doi.org/10.1080/02667360903151767 
Mansfield, K. C., Fowler, B., \& Rainbolt, S. (2018). The Potential of Restorative Practices to Ameliorate Discipline Gaps: The Story of One High School's Leadership Team. Educational Administration Quarterly, 54(2), 303-323. https:// doi.org/10.1177/0013161X17751178

Merrell, K. W., \& Gueldner, B. A. (2012). Social and emotional learning in the classroom: Promoting mental health and academic success. Guilford Press.

Miles, B.M., Huberman, A.M., \& Saldana, J. (2014). Qualitative Data Analysis: A Methods Sourcebook. (3rd. Ed). Los Angeles: Sage.

Morrison, B., Blood, P., \& Thosborne, M. (2005). Practicing restorative justice in school communities: The challenge of culture change. Public Organization Review, 5, 335-357.

Mullet, J. H. (2014). Restorative discipline: From getting even to getting well. Children \& Schools, 36(3), $157-162$.

Noltemeyer, A. L., Ward, R. M., \& Mcloughlin, C. (2015). Relationship Between School Suspension and Student Outcomes: A Meta-Analysis. School Psychology Review, 44(2), 224-240. https://doi. org/10.17105/spr-14-0008.1

Oberle, E., Domitrovich, C. E., Meyers, D. C., \& Weissberg, R. P. (2016). Establishing systemic social and emotional learning approaches in schools: A framework for schoolwide implementation. Cambridge Journal of Education, 46(3), 277-297. https://doi.org/10.1080/0305764X.2015.1125450

Oberle, E., \& Schonert-Reichl, K. A. (2017). Social and Emotional Learning: Recent Research and Practical Strategies for Promoting Children's Social and Emotional Competence in Schools. In J. L. Matson (Ed.), Handbook of Social Behavior and Skills in Children (pp. 175-197). Cham, Switzerland: Springer International Publishing. https://doi.org/10.1007/978-3-319-64592-6_11

Ottmar, E. R., Rimm-Kaufman, S. E., Larsen, R. A., \& Berry, R. Q. (2015). Mathematical Knowledge for Teaching, Standards-Based Mathematics Teaching Practices, and Student Achievement in the Context of the Responsive Classroom Approach. American Educational Research Journal, 52(4), 787-821. https://doi. org/10.3102/0002831215579484
Panayiotou, M., Humphrey, N., \& Wigelsworth, M. (2019). An empirical basis for linking social and emotional learning to academic performance. Contemporary Educational Psychology, 56, 193-204. https://doi.org/10.1016/j. cedpsych.2019.01.009

Panter-Brick, C., Clarke, S. E., Lomas, H., Pinder, M., \& Lindsay, S. W. (2006). Culturally compelling strategies for behaviour change: A social ecology model and case study in malaria prevention. Social Science \& Medicine, 62(11), 2810-2825. https://doi.org/10.1016/j. socscimed.2005.10.009

Schonert-Reichl, K. A. (2019). Advancements in the Landscape of Social and Emotional Learning and Emerging Topics on the Horizon. Educational Psychologist, 54(3), 222-232. https:// doi.org/10.1080/00461520.2019.1633925

Schonert-Reichl, K. A., Oberle, E., Lawlor, M. S., Abbott, D., Thomson, K., Oberlander, T. F., \& Diamond, A. (2015). Enhancing Cognitive and SocialEmotional Development Through a Simple-toAdminister Mindfulness-Based School Program for Elementary School Children: A Randomized Controlled Trial. Developmental Psychology, 51(1), 52-66. https://doi.org/10.1037/a0038454

Smith, B. H., \& Low, S. (2013). The Role of Social-Emotional Learning In Bullying Prevention Efforts. Theory Into Practice, 52(4), 280-287. https://doi.org/10.1 080/00405841.2013.829731

Stake, R.E. (2006). Multiple Case Study Analysis. New York: Guilford Press.

Stokols, D. (1992). Establishing and maintaining healthy environments: Toward a social ecology of health promotion. American Psychologist, 47(1), 6-22. https://doi.org/10.1037/0003-066X.47.1.6

Sumner, M. D., Silverman, C. J., \& Frampton, M. L. (2010). School-based restorative justice as an alternative to zero-tolerance policies: Lessons from West Oakland. Berkeley, CA: Thelton E. Henderson Center for Social Justice, University of California, Berkeley, School of Law.

United States Department of Education. (2021, February 20). Race to the Top District Competitions Draft Definitions. Retrieved from https://www.ed.gov/ racetop/districtcompetition/definitions 
Vadeboncoeur, J. A., \& Collie, R. J. (2013). Locating Social and Emotional Learning in Schooled Environments: A Vygotskian Perspective on Learning as Unified. Mind, Culture, and Activity, 20(3), 201-225. https://doi.org/10.1080/10749039. 2012.755205

Vygotsky, L.S. (1978). Mind in society: The development of higher psychological processes. Cambridge, MA: Harvard University Press

Wachtel, T. (2012). Defining restorative. Retrieved from http://iirpds.pointinspace.com/pdf/ DefiningRestorative.pdf

Watchel, T. (2013). Dreaming of a New Reality: How Restorative Practices Reduce Crime and Violence, Improve Relationships and Strengthen Civil Society. Bethlehem, PA: The Piper's Press.

Weissbourd, R., Bouffard, S. M., \& Jones, S. M. (2013). School climate and moral and social development. School Climate Practices for Implementation and Sustainability, 30, 1-5.

Wigelsworth, M., Lendrum, A., Oldfield, J., Scott, A., ten Bokkel, I., Tate, K., \& Emery, C. (2016). The impact of trial stage, developer involvement and international transferability on universal social and emotional learning programme outcomes: A meta-analysis. Cambridge Journal of Education, 46, 347-376.

Zinsser, K. M., Shewark, E. A., Denham, S. A., \& Curby, T. W. (2014). A Mixed-Method Examination of Preschool Teacher Beliefs About SocialEmotional Learning and Relations to Observed Emotional Support. Infant and Child Development, 23(5), 471-493. https://doi. org/10.1002/icd.1843 